\title{
PRENHEZ EM REBANHOS OVINOS DO RIO GRANDE DO SUL
}

\author{
PREGNANCY ON SHEEP FLOCKS OF THE STATE OF \\ RIO GRANDE DO SUL-BRAZIL
}

\author{
Luiz Alberto Oliveira Ribeiro ${ }^{1}$ Ricardo Macedo Gregory ${ }^{2}$ Rodrigo Costa Mattos ${ }^{2}$
}

RESUMO

No presente trabalho, são apresentados dados sobre o diagnóstico de gestação realizado por ultra-sonografia em 45 rebanhos ovinos, durante seis periodos reprodutivos. Foram examinadas 27.089 ovelhas de rebanhos comerciais, acasaladas durante o outono. A porcentagem de prenhez $(P P)$ variou de 77,3 a 89,9\%, com uma PP média de 81,6\%. Rebanhos de raças de carne (Hampshire Down, Suffolk e Texel) mostram em média a PP mais elevada que foi de 85,6\%, seguidos de ovelhas cruzas, com PP de 82,9\% e finalmente ovelhas de raças de lã (Merino Australiano, Corriedale e Ideal) com PP média de 80,8\%. Prováveis causas de baixas PP observadas em alguns rebanhos são apresentadas e discutidas.

Palavras-chave: ovinos, porcentagem de prenhez.

\section{SUMMARY}

In this paper, data from real-time ultrasound pregnancy diagnosis carried out in 45 sheep flock during six reproductive seasons are presented. A total of 27089 ewes from commercial flocks, mated during autumn, were scanned. The mean pregnancy percentage $(P P)$ found was $81.6 \%$ showing a variation from 77.3 to $89.9 \%$. Mutton breed flocks (Hampshire Down, Suffolk and Texel) showed the highest PP of $85.6 \%$, followed by cross breeds, with a PP of $82.9 \%$. The PP of wool breeds flocks (Australian Merino, Corriedale and Polwarth) was $80.8 \%$. The causes of low PP founded on some flocks is presented and discussed.

Key words: sheep, pregnancy percentage

\section{INTRODUÇÃO}

A população ovina do Rio Grande do Sul (RS), tem apresentado um declínio desde 1978, quando atingiu 13 milhões de cabeças, chegando, assim, aos valores atuais estimados de 4,4 milhões (ANUALPEC,1999). Essa diminuição tem sido associada ao baixo preço da lã nos mercados internacionais. Contribuem, também, para a diminuição do rebanho gaúcho, problemas sanitários (helmintoses, footrot) e reprodutivos, representados por alta mortalidade de cordeiros e baixa fertilidade.

Até recentemente, a ovinocultura gaúcha foi essencialmente dirigida para a produção de lã. Os rebanhos eram criados em condições extensivas e em regiões menos favoráveis à agricultura. Nesse sistema, a quantidade e qualidade da lã são os parâmetros mais críticos, sendo a eficiência reprodutiva um fator secundário, uma vez que a economicidade não ficará comprometida mesmo frente a níveis baixos de desmame de cordeiros. Entretanto, mais recentemente, os ovinocultores gaúchos viram na indústria do cordeiros uma alternativa mais rentável. Nesse novo sistema, de característica mais intensiva, a eficiência reprodutiva torna-se um fator preponderante, uma vez que o aspecto econômico está alicerçado na produção de cordeiros, pois a quantidade e qualidade da lã

\footnotetext{
${ }^{1}$ Médico Veterinário, Mestre, Professor Adjunto, Departamento de Medicina Animal Universidade Federal do Rio Grande do Sul (UFRGS), Av. Bento Gonçalves 9090, Porto Alegre, 91540-000. E-mail: bertorib@adufrgs.ufrgs.br. Autor para correspondência.

${ }^{2}$ Médico Veterinário, Doutor, Professor Adjunto, Departamento de Medicina Animal, UFRGS. 
produzida pelas raças de carne são de baixo valor comercial.

Dados sobre taxa de prenhez em rebanhos comerciais são pouco mencionadas na literatura internacional. LEES (1978) citou que, no Reino Unido, em rebanhos monitorados pelo Meat and Livestock Commission (MLC), a percentagem de ovelhas vazias variou entre $10,3 \mathrm{e}$ $11,2 \%$ e que, pelo menos, $10 \%$ dos rebanhos mostraram índices de ovelhas vazias entre 11 e $15 \%$. Por outro lado, o desempenho reprodutivo de rebanhos ovinos comerciais do RS tem sido pouco estudado. OLIVEIRA (1978) menciona índices de fertilidade de $60 \%$ e um percentual de mortalidade perinatal de cordeiros de 25\%. COIMBRA FLIHO (1975) observou taxa de parição entre 90,5 e 92\% em rebanho Ideal. Entretanto, dados sobre taxa de prenhez em rebanhos comerciais não são disponíveis.

Mais recentemente, com a utilização da ultra-sonografia como eficiente método de diagnóstico de gestação em ovinos, está sendo possível obter dados sobre taxas de prenhez em rebanhos gaúchos. COW (1991) examinou oito mil ovelhas de rebanhos criados no município de Santana do Livramento - RS, encontrando percentagens de ovelhas vazias entre 5 a $40 \%$ com valor médio de $15 \%$. O presente estudo teve como objetivos: (a) levantar informações sobre as percentagens de prenhez de rebanhos ovinos criados em diversas áreas geográficas do RS e (b) comparar as porcentagens de prenhez das diversas raças ovinas criadas no RS.

\section{MATERIAL E MÉTODOS}

As ovelhas examinadas, neste estudo, foram de 45 rebanhos comerciais, criados em 23 municípios do RS, compreendendo cinco áreas geográficas, conforme consta da tabela 1. Os rebanhos estudados foram das raças Corriedale, Ideal, Merino Australiano, Suffolk, Texel, e Hampshire Down. Alguns rebanhos cruzas dessas raças foram também incluídos. Todos os rebanhos estudados foram manejados com bovinos, de forma extensiva e com alimentação exclusiva em gramíneas de campos naturais. O manejo sanitário segue recomendações convencionais como dosificação antihelmíntica antes do encarneiramento e vacinação contra a clostridiose. Somente ovelhas adultas foram incluídas no estudo.

As ovelhas foram encarneiradas durante os meses de outono (março-abril), por 60 dias e por monta natural. Antes do encarneiramento, foram retiradas ovelhas com desgaste dentário excessivo e aquelas que mostravam lesões graves na vulva e úbere. Os carneiros usados foram submetidos a exame dos órgãos genitais externos e exame biológico do sêmen obtido por eletro-ejaculação. Foram usados somente carneiros que apresentaram resultados compatíveis com os de animais férteis.

O diagnóstico de gestação foi realizado entre 50 a 100 dias após a retirada dos carneiros, sendo as ovelhas examinadas em estação, sem jejum prévio, usando-se um brete a $40 \mathrm{~cm}$ do chão. $O$ exame foi realizado na região inguinal direita do animal, com um aparelho de ultra-sonografia Vetscan 2, equipado com um transdutor setorial de 3,5 Mhz.

Os dados de cada rebanho, referentes ao número de ovelhas prenhes, número de ovelhas vazias e total de ovelhas examinadas, foram registrados em fichas individuais por propriedade. A porcentagem de prenhez foi calculada conforme fórmula:

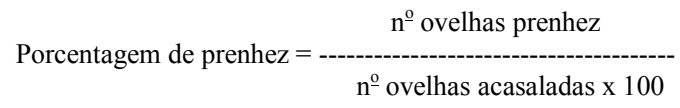

As PP encontradas nos diferentes grupos raciais foram submetidas ao teste do Quiquadrado.

\section{RESULTADOS}

Os dados dos diagnósticos de gestação realizados em ovinos durante seis períodos reprodutivos, nas diversas regiões geográficas do RS são mostrados na tabela 2. Foram examinadas um total de 27.089 ovelhas de 45 rebanhos do RS. A PP variou de $77,3 \%$ a $89,9 \%$, sendo que a porcentagem de prenhez média ficou em $81,6 \%$. Analisando os dados da tabela 2, verifica-se que, com exceção dos resultados coletados em 1993, quando a PP observada foi de somente $77,3 \%$, as taxas de prenhez flutuaram entre 80 a $90 \%$.

A tabela 3 mostra a PP por raças de ovinos nos rebanhos estudados. Foram aqui, 
Tabela 2 - Porcentagem de prenhez (PP) em rebanhos ovinos do $\mathrm{RS}$ em seis períodos reprodutivos.

\begin{tabular}{lllll}
\hline Ano & $\mathrm{n}^{\mathrm{o}}$ rebanhos & $\begin{array}{l}\mathrm{n}^{\mathrm{o}} \text { ovelhas } \\
\text { examinadas }\end{array}$ & $\begin{array}{l}\mathrm{n}^{\mathrm{o}} \text { ovelhas } \\
\text { prenhes }\end{array}$ & PP \% \\
\hline 1992 & $11^{\mathrm{a}, \mathrm{b}, \mathrm{c}, \mathrm{e}^{*}}$ & 3814 & 3067 & 80,4 \\
1993 & $09^{\mathrm{a}, \mathrm{b}, \mathrm{c}, \mathrm{e}}$ & 10543 & 8152 & 77,3 \\
1994 & $14^{\mathrm{a}, \mathrm{b}, \mathrm{c}, \mathrm{d}}$ & 8188 & 7214 & 88,1 \\
1995 & $06^{\mathrm{b}, \mathrm{c}, \mathrm{d}, \mathrm{e}}$ & 3699 & 2968 & 80,2 \\
1998 & $03^{\mathrm{c}, \mathrm{d}}$ & 426 & 347 & 81,4 \\
2000 & $02^{\mathrm{c}}$ & 419 & 377 & 89,9 \\
Total & 45 & 27089 & 22125 & 81,6 \\
\hline
\end{tabular}

*Regiões: $\mathrm{a}=$ Região Sul; $\mathrm{b}=$ Fronteira Oeste; $\mathrm{c}=$ Depressão Central; $\mathrm{d}=$ Planalto/Serra; $\mathrm{e}=$ Litoral/outras.

considerados somente os valores dos rebanhos que tinham definição racial ou suas cruzas. Assim, a tabela 3 mostra que foram estudados 23 rebanhos de raças produtoras de lã, 17 rebanhos de raças de carne e mais 5 rebanhos de ovelhas obtidas do cruzamento de raças de lã com raças de carne.

Embora o número de rebanhos e mesmo o número de ovelhas examinadas não sejam equivalentes, a média da PP das raças produtoras de lã $(80,8 \%)$ foi inferior $(\mathrm{p}<0,01)$ a PP das raças produtoras de carne, cujo valor médio foi de $85,6 \%$. Por outro lado, a PP média de quatro rebanhos cruzas mostrou valor de $82,9 \%$, intermediário entre as raças de carne e lã. Os dados da tabela 2 mostram também que não foi observada grande variação entre as PP das ovelhas produtoras de lã e que a taxa média de ovelhas vazias nesse grupo de animais foi de 18 a $20 \%$, o que pode ser tolerado por esse sistema de produção, cujo propósito primário é a lã.

Já o grupo de ovelhas de raças produtoras de carne, no qual as taxas de prenhez têm um significado importante, refletindo diretamente no número de cordeiros produzidos, mostraram valores preocupantes e, de certa forma, variáveis. A PP média mais elevada, observada em 7 rebanhos Texel, chegou a 92,7\%, indicando que rebanhos de raças de carne, bem manejado, podem atingir altas taxas de prenhez. As ovelhas cruzas, por outro lado, mostraram uma PP média intermediária de 82,9, refletindo, de certa forma, maior fertilidade resultante do cruzamento.

\section{DISCUSSÃO}

No presente trabalho, dados sobre a PP de 45 rebanhos ovinos criados em cinco diferentes áreas geográficas do RS são apresentados. A PP média encontrada, referente a seis anos reprodutivos, foi de $81,6 \%$. No RS, dados sobre PP em ovinos são escassos. As primeiras referências sobre o uso da ultra-sonografia em pequenos ruminantes em nosso meio foram de ALVES $\boldsymbol{e}$ t al. (1991) e BERNARDI \& FAGUNDES (1991). Esses autores avaliaram o uso da ultra-sonografia abdominal, testando sua eficácia em vários estágios da gestação. Os achados estão em concordância com a literatura internacional sobre o tema que sugere o período compreendido entre 50 a 100 dias de gestação, usado no presente trabalho, como o mais conveniente para a realização desse exame que chega a índices de acerto para prenhez de 96\% (ALVES et al.,1991).

A PP média encontrada nos rebanhos ovinos comerciais do RS, no presente estudo, está bastante próxima da encontrada por ALVES et al. (1991). Esses autores, em um estudo realizado em 1226 ovelhas das raças Corriedale, Romney Marsh, Suffolk e Ile de France, encontraram um valor médio de 79\% de prenhez. Dados obtidos por COW (1991) em mais de vinte rebanhos ovinos de Santana do Livramento (RS) revelou PP entre 85 e $95 \%$. O autor cita que, em alguns rebanhos, a PP foi de somente $60 \%$.

Os dados da tabela 3 nos mostram as PP por raças de ovinos nas quais os valores percentuais de prenhez para as raças ovinas de lã foram inferiores aos valores das raças de carne que, na sua origem, foram selecionadas para eficiência reprodutiva. Na mesma tabela, os valores de PP para as ovelhas cruzas de raças de lã com raças de carne mostram um valor intermediário entre suas raças de origem. Na Nova Zelândia, onde a ovinocultura é dirigida para a produção de cordeiro, a partir de ovelhas cruzas a porcentagem média de ovelhas

Tabela 3 - Porcentagem de prenhez (PP) de raças ovinas do RS em seis períodos reprodutivos.

\begin{tabular}{lccc}
\hline Raça & $\begin{array}{c}\mathrm{n}^{\circ} \text { de } \\
\text { rebanhos }\end{array}$ & $\begin{array}{c}\mathrm{n}^{\circ} \text { de ovinos } \\
\text { examinados }\end{array}$ & PP\% \\
\hline Merino Australiano & 7 & 11649 & 80,0 \\
Corriedale & 9 & 5492 & 82,0 \\
Ideal & 7 & 3857 & 82,0 \\
Sub-total & 23 & 20998 & $80,8 \mathrm{a}$ \\
Texel & 7 & 1449 & 92,7 \\
Suffolk & 8 & 1623 & 81,3 \\
Hampshire Down & 2 & 237 & 71,7 \\
Sub-total & 17 & 3309 & $85,6 \mathrm{~b}$ \\
Corriedale x Suffolk & 2 & 1980 & 82,8 \\
Corriedale x Ile de France & 1 & 641 & 82,3 \\
Texel x B. Leicester & 2 & 161 & 86,3 \\
Sub-total & 5 & 2782 & $82,9 \mathrm{c}$ \\
Total & 45 & 27089 & 81,6 \\
\hline
\end{tabular}

a,b,c $(\mathrm{p}<0,01)$ letras diferentes representam diferenças significativas. 
vazias é de 4\% (ALISON, 1983), bastante inferior ao índice médio encontrado para esse grupo genético no presente estudo. Na Austrália, ABBOTT et al. (1996) citam que em rebanhos produtores de lã, a porcentagem média de ovelhas vazias é de $8 \%$, também inferior aos valores encontrados em ovinos laneiros do RS.

A literatura cita que baixas taxas de prenhez em rebanhos ovinos, em geral, tem origem multifatorial e, por isso, deverá ser considerado o manejo reprodutivo, sanitário e, principalmente o nutricional. Em nosso meio, ovelhas de raças produtoras de lã, por terem uma exigência nutricional menor e com mais de 70 anos de adaptação ao meio ambiente, mostram PP compatível com esse sistema de produção, onde as perdas reprodutivas são, de certa forma, compensadas pela maior produção de lã das ovelhas não gestantes. Por outro lado, as ovelhas de raças produtoras de carne, que geneticamente foram selecionadas para a produção de cordeiros, não encontram nas condições extensivas a campo, suporte nutricional adequado para a manifestação de sua habilidade reprodutiva. Os dados da tabela 3 mostram, entretanto, que, embora um pequeno número de ovelhas examinadas da raça Hampshire Down tenha revelado a menor PP encontrada nesse estudo, no mesmo grupo os rebanhos Texel mostraram a mais alta PP que foi $92,7 \%$. Esses dados sugerem que rebanhos de raças de carne necessitam de um maior atenção em seu manejo nutricional e que, quando bem manejados, podem evidenciar altos índices de fertilidade.

Em uma revisão sobre causas de perdas reprodutivas em ovinos na América Latina, SILVA (1992) menciona três fatores principais que são: (a) manejo nutricional e reprodutivo deficiente; (b) mortalidade perinatal de cordeiros e (c) enfermidades como footrot, miiases etc. Segundo o autor, esses fatores contribuiriam de diferentes maneiras para a redução da condição corporal (CC), tendo assim um efeito direto na eficiência reprodutiva das ovelhas. OLIVEIRA \& MORAES (1991) observando a idade e a estrutura de rebanhos Corriedale no Sul do Brasil observaram que borregas e ovelhas velhas devem ser tratadas diferentemente de outras fềmeas do rebanho durante o período pós-parto para que se consiga aumento na taxa de desmame. A avaliação da $\mathrm{CC}$ das ovelhas antes do encarneiramento, prática comum em outros países, é praticamente desconhecida em nosso meio. No presente estudo, não foi possível coletar dados de idade e condição corporal das ovelhas que poderá ser objetivo de outros trabalhos.

Ao examinar as causas de perdas reprodutivas em ovinos, muitos autores têm dado importância ao período inicial da embriogênese, que ocorre entre a fertilização e os dias 20-30 da gestação. Estima-se que 20 a $30 \%$ dos ovos fertilizados são perdidos nesse período (BRUÈRE \& WEST, 1993). No RS, MORAES (1992) observou os mesmos valores, considerando a incidência de mortalidade embrionária e fetal como a principal fonte de perdas econômicas para a produção ovina local.

É importante salientar que as PP encontradas neste trabalho, embora toleradas em sistemas de produção laneira, tornam-se críticas em sistema de produção de cordeiros. No RS, há uma crença entre criadores e técnicos que a simples introdução de carneiros de raça de carne em um rebanho aumentará a fertilidade e a taxa de desmame de cordeiros. Os dados do presente trabalho, de certa forma, suportam essa afirmação, pois a PP observada em rebanhos cruzas foi superior à $\mathrm{PP}$ de rabanhos de raças de lã. Entretanto, as PP reveladas para as raças de carne e suas cruzas $(85,6$ e $82,9 \%)$ estão abaixo dos índices observados em sistemas de produção de cordeiros da Nova Zelândia e Austrália. Assim, a plena utilização do potencial genético das raças produtoras de carne introduzidas no RS dependerá de maior atenção aos manejos reprodutivo e principalmente nutricional.

O presente trabalho procurou levantar dados sobre percentagens de prenhez observadas em rebanhos comerciais do RS. Os dados mostram que as porcentagens de prenhez de nossos rebanhos são inferiores às observadas em rebanhos de países mais desenvolvidos. Os dados sugerem que novos trabalhos deverão ser realizados tentando identificar quais as principais causas dessas perdas.

\section{REFERÊNCIAS BIBLIOGRÁFICAS}

ABBOTT, K.A., MILLER, B.G., NICHOLAS, F.W., et al. Sheep health \& production: a course for veterinary science students. 2.ed. Sydney : Sydney University, 1996. Cap.7: Reproductive managment: 7.1-7.56.

ALLISON, A.J. Review: The management of mating for maximum fertilization and conception. In: SEMINAR NZVA SHEEP \& CATTLE SOCIETY, 13, 1983. Proceedings. Nova Zelândia : NZVA Sheep \& Cattle Society, 1983. p.76-90.

ALVES, L.C., NEVES, J.P., LUZ, S.L.N. Avaliação da ultrasonografia abdominal para o diagnóstico de gestação em ovelhas. In: CONGRESSO BRASILEIRO DE REPRODUÇÃO ANIMAL, 1991, Belo Horizonte, MG. Resumos... Belo Horizonte : Colégio Brasileiro de Reprodução Animal, 1991. 470p. p.398. 
ANUALPEC- Anuário da Pecuária Brasileira. Rebanho ovino no Brasil. São Paulo : Argos Comunicações, 1999. p.359.

BERNARDI, M.L., FAGUNDES, M.D. Diagnóstico de gestação em caprinos através de ultra-som. In: CONGRESSO BRASILEIRO DE REPRODUÇÃO ANIMAL, 1991, Belo Horizonte, MG. Resumos... Belo Horizonte : Colégio Brasileiro de Reprodução Animal, 1991. 470p. p.396.

BRUĖRE, A.M., WEST, D.M. The sheep: health, diseases \& production. Palmerston North, New Zealand : Massey University, 1993. Chapter 3: Factors affecting lamb production and the investigation of poor lambing: p.36-55.

COIMBRA FILHO, A. Influência de duas épocas de cobertura nos nascimentos, sobrevivência e desenvolvimento dos cordeiros. Porto Alegre-RS, 1975. 95p. Dissertação (Mestrado em Agronomia) - Faculdade de Agronomia, Universidade Federal do Rio Grande do Sul, 1975.

COW, A. Observações da produção ovina na região da fronteira do Rio Grande do Sul. Santana do Livramento : Edigraf, 1991. 79p.
LEES, J.L. Functional infertility in sheep. Veterinary Record, v.102, p.232-236, 1978.

MORAES, J.C.F. A mortalidade embrionária e a eficácia da inseminação artificial em ovinos. Ciência Rural, Santa Maria, v.22, n.3, p.367-372, 1992.

OLIVEIRA, A.C. Mortalidade perinatal em ovinos no Rio Grande do Sul referência especial ao diagnóstico. Santa Maria-RS, 1978, 74p. Dissertação (Mestrado em Medicina Veterinária) - Faculdade de Veterinária, Universidade Federal de Santa Maria, 1978.

OLIVEIRA, N.M., MORAES, J.C.F. Age and flock structure on the reproductive performance of corriedale ewes in southern Brazil. Revista Brasileira de Reprodução Animal, v.15, n.3-4, p.133-143, 1991.

SILVA, C.A.M. Reproductive wastage in sheep. Santa Maria : Universidade Federal de Santa Maria - FAO - UNO, 1992. 45p. 